\title{
Bioavailability, Antipsoriatic Efficacy and Tolerability of a New Light Cream with Mometasone Furoate $\mathbf{0 . 1 \%}$
}

\author{
H.C. Korting ${ }^{a} \quad$ C. Schöllmann ${ }^{a} \quad$ C. Willers ${ }^{b} \quad$ W. Wigger-Albertic \\ a Department of Dermatology and Allergology, Ludwig Maximilian University, Munich, b Almirall Hermal, Reinbek, \\ and 'bioskin $\mathrm{GmbH}$, Hamburg, Germany
}

\section{Key Words}

Mometasone furoate $\cdot$ Light cream $\cdot$ Vasoconstriction assay $\cdot$ Psoriasis plaque test

\begin{abstract}
Mometasone furoate, a potent glucocorticoid (class III) with a favorable benefit/risk ratio, has emerged as a standard medication for the treatment of inflammatory skin disorders. The purpose of the investigation presented here was to determine the noninferiority of a topical mometasone formulation, a light cream (O/W 60/40 emulsion) with mometasone furoate $0.1 \%$ (water content of $33 \%$ ) versus marketed comparators. Using the vasoconstrictor assay, a strong blanching effect of the new cream (called Mometasone cream) comparable to that of a mometasone comparator, a fatty cream with mometasone furoate $0.1 \%$, could be demonstrated. Thus, the topical bioavailability of the active ingredient mometasone furoate $(0.1 \%)$ was regarded to be similar for Mometasone cream and the mometasone comparator. Using the psoriasis plaque test, a strong antipsoriatic effect comparable to that of the mometasone comparator was found for Mometasone cream after 12 days of occlusive treatment. A nearly identical reduction in the mean infiltrate thickness and similar mean AUC values were noted with both formulations confirmed by clinical assessment data. The noninferiority of Mometasone cream to its active comparator with re-
\end{abstract}

spect to the AUC of change to baseline in infiltrate thickness was demonstrated. Both medications were well tolerated. Overall, Mometasone cream and the mometasone comparator showed similar efficacy and tolerability. Mometasone cream, in addition to its high potency and good tolerability, provides the properties of a light cream, which might make this new medication particularly suitable for application on acutely inflamed and sensitive skin.

Copyright ๑ 2012 S. Karger AG, Basel

\section{Introduction}

Establishing topical glucocorticoid therapy has been one of the most significant advances in dermatology [1]. For five decades these agents have been used in the treatment of skin diseases due to their undebatable potency in reducing inflammation [1-3]. Besides their anti-inflammatory potency, corticosteroids show a wide-ranging spectrum of actions including antimitotic activity [4] and immunosuppressive effects, which are at least partly attributable to the inhibition of the release of various cytokines [3]. Since the introduction of hydrocortisone for topical use, more potent glucocorticoid congeners have been developed.

The long-term use of topical glucocorticoids is still limited by both topical and systemic side effects with skin

\section{KARGER}

Fax +4161306 1234 E-Mail karger@karger.ch www.karger.com

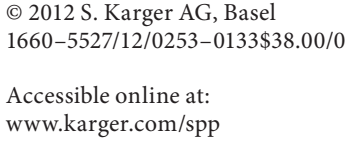

Prof. Dr. med. Hans Christian Korting

Department of Dermatology and Allergology

Ludwig Maximilian University

Frauenlobstrasse 9-11, DE-80337 Munich (Germany)

Tel. +49 895160 6154, E-Mail H.C.Korting@lrz.uni-muenchen.de 
atrophy [4] and suppression of the hypothalamic pituitary axis being of particular concern. Thus, pertinent research today mainly focuses on the improvement of the benefit/risk ratio of glucocorticoids [2]. Apart from designing new active congeners, a further issue is the development of formulations with properties reflecting the current state of the skin [5] and the differing expectations of the patients.

The development of mometasone furoate, a $\left(2^{\prime}\right)$ furoate-17 ester with chlorine substituents at positions 9 and 21 [3], has been a result of efforts to separate the wanted from the unwanted effects of topically applied glucocorticoids. This corticoid combines high potency (classification as a class III, i.e. high-strength steroid according to Braun-Falco et al. [6]) with low systemic availability after topical administration. The resulting low systemic toxicity reflects an improved risk-benefit profile, compared to previous moderately potent topical glucocorticoids $[7,8]$. Due to its low percutaneous absorption, together with rapid hepatic biotransformation, topically applied mometasone furoate does not show a significant effect on the hypothalamic pituitary axis [3]. Furthermore, its atrophogenic potential and risk of sensitization are considered low [9]. Thus, the therapeutic effects clearly outweigh the unwanted effects; correspondingly, a therapeutic index of 2.0 has been attributed to this glucocorticoid [10]. Today, mometasone furoate is established as a topical standard medication in the management of patients with inflammatory skin disorders [9].

Topical glucocorticoids are formulated in a variety of vehicles such as ointments, creams, lotions and gels [11]. The efficacy of a glucocorticoid formulation is considerably influenced by its vehicle [12]. This also applies to mometasone furoate [8]. In fact, the vehicle has a great influence on the agent's penetration into the stratum corneum and, consequently, on the local bioavailability and efficacy of the glucocorticoid [11, 13-15]. A generic glucocorticoid preparation is therefore not necessarily interchangeable with the respective originator product, unless its vehicle and, correspondingly, its topical availability are exactly the same. For approval, a generic topical preparation has to undergo investigations to prove its bioequivalence with the originator product. Several test methods, among them the psoriasis plaque test (PPT) and the vasoconstrictor test, have been established as tools to compare the topical efficacy of glucocorticoid preparations [16].

Ointments are often considered to be of a higher potency than creams containing the same concentration of the active ingredient, probably due to their occlusive ef- fect which may increase stratum corneum hydration and enhance drug transport [11]. In contrast, Korting et al. [17] could show earlier by means of a vasoconstrictor assay that a cream and a respective ointment containing the same concentration of mometasone furoate do not necessarily differ in their activity. Generally, ointments are preferred in the treatment of infiltrated, lichenified lesions and creams for acute und subacute dermatoses, whereas lotions and gels are considered particularly suitable for scalp psoriasis [11]. Patients themselves might particularly like light creams with respect to convenient daily application [publication in preparation]. This should be taken into account in dermatological therapy as patient compliance is crucial for treatment success [18].

The purpose of the studies presented here was to determine the noninferiority of a new light cream formulation with the same content of the active ingredient mometasone furoate of $0.1 \%$ as the originator, but with a higher water content of $33 \%$ compared to the originator cream with a water content of below $5 \%$ and a higher amount of lipids. The bioavailability of the formulations has been evaluated by means of a vasoconstrictor assay, and the antipsoriatic efficacy in a PPT. In both trials, safety issues have been observed concomitantly.

A vasoconstrictor assay under standardized conditions is well suited for assessing the in vivo bioavailability of topical dermatological corticosteroids in humans. It is based on the property of corticosteroids to induce vasoconstriction represented by blanching of the skin [19-21]. The vasoconstrictive strength is known to correlate strongly with the clinical efficacy of topical glucocorticoids as determined in clinical treatment trials [22].

Since its introduction by Dumas and Scholtz [23] in 1972, the PPT is recognized as a suitable method for the assessment of antipsoriatic action. The clinical relevance of the test results has been demonstrated [24].

Dermal tolerability of the new formulation was determined following repeated application of the drug during a 21-day treatment period.

\section{Materials and Methods}

All studies were performed by bioskin $\mathrm{GmbH}$, Hamburg, Germany, in accordance with the 'Somerset West' Declaration of Helsinki (October 1996) as well as German regulations. The ICH guideline for Good Clinical Practice (January 1997) was observed. The study protocol and other relevant documents were submitted to the Ethics Committee of the Hamburg Medical Council for review prior to the initiation of the study. Approval was granted for performance of the studies as outlined in the protocol. There were no amendments. 
Table 1. Ingredients of the test and reference products

\begin{tabular}{|c|c|c|c|c|}
\hline Mometasone cream & $\begin{array}{l}\text { Vehicle to Mometasone } \\
\text { cream }\end{array}$ & $\begin{array}{l}\text { Mometasone } \\
\text { comparator }\end{array}$ & Clobetasol cream & Triamcinolone cream \\
\hline $\begin{array}{l}1 \mathrm{mg} / \mathrm{g} \text { of mometasone } \\
\text { furoate } \\
\text { water content } 33 \%\end{array}$ & water content $33 \%$ & $\begin{array}{l}1 \mathrm{mg} / \mathrm{g} \text { of } \\
\text { mometasone furoate } \\
\text { water content }<5 \%\end{array}$ & $\begin{array}{l}0.5 \mathrm{mg} / \mathrm{ml} \text { of } \\
\text { clobetasol-17- } \\
\text { propionate } \\
\text { water content } 30.8 \% *\end{array}$ & $\begin{array}{l}1 \mathrm{mg} / \mathrm{g} \text { of } \\
\text { triamcinolone } \\
\text { acetonide } \\
\text { water content } 72.2 \% \text { * }\end{array}$ \\
\hline $\begin{array}{l}\text { Purified water, white soft } \\
\text { paraffin (contains butylated } \\
\text { hydroxytoluene as } \\
\text { antioxidant), liquid } \\
\text { paraffin, } \\
\text { 2-methylpentane-2,4-diol, } \\
\text { emulsifying cetostearyl } \\
\text { alcohol (type A, contains } \\
\text { disodium/potassium } \\
\text { hydrogen phosphate for pH } \\
\text { adjustment), macrogol, } \\
\text { cetostearyl ether cetyl } \\
\text { alcohol, glycerol, anhydrous } \\
\text { citric acid, sodium citrate, } \\
\text { xanthan gum }\end{array}$ & $\begin{array}{l}\text { Purified water, white soft } \\
\text { paraffin (contains butylated } \\
\text { hydroxytoluene as } \\
\text { antioxidant), liquid paraffin, } \\
\text { 2-methylpentane-2,4-diol, } \\
\text { emulsifying cetostearyl } \\
\text { alcohol (type A, contains } \\
\text { disodium/potassium } \\
\text { hydrogen phosphate for pH } \\
\text { adjustment), macrogol, } \\
\text { cetostearyl ether cetyl } \\
\text { alcohol, glycerol, anhydrous } \\
\text { citric acid, sodium citrate, } \\
\text { xanthan gum }\end{array}$ & $\begin{array}{l}\text { White soft paraffin, } \\
\text { hexylene glycol, } \\
\text { aluminium starch, } \\
\text { octenylsuccinate, } \\
\text { propylene } \\
\text { glycolstearate, } \\
\text { stearyl alcohol, } \\
\text { ceteareth-20, white } \\
\text { beeswax, titanium } \\
\text { dioxide, phosphoric } \\
\text { acid, purified water }\end{array}$ & $\begin{array}{l}\text { Chlorocresol, glyceryl } \\
\text { monostearate, } \\
\text { cetostearyl alcohol, } \\
\text { Arlacel } 165 \text {, beeswax } \\
\text { substitute } 6621 \text {, } \\
\text { sodium citrate, citric } \\
\text { acid monohydratete, } \\
\text { propylene glycol, } \\
\text { purified water }\end{array}$ & $\begin{array}{l}\text { Phenoxyethanol } 3.6 \\
\text { mg, decyloleate, } \\
\text { cetylstearyl alcohol, } \\
\text { cetomacrogol } 1000 \text {, } \\
\text { propylene glycol, } \\
\text { dimeticon } 20 \text {, citric } \\
\text { acid waterfree, } \\
\text { sodium hydrogen } \\
\text { phosphate } 2 \mathrm{H}_{2} \mathrm{O} \text {, } \\
\text { water }\end{array}$ \\
\hline
\end{tabular}

* Determined by Karl Fischer titration.

Vasoconstriction Assay

Test Subjects and Medication

The aim of the study was to determine the bioavailability of topical mometasone cream formulations, each containing $0.1 \%$ mometasone furoate, in a vasoconstrictor assay in subjects with healthy skin. Between April and May 2008, 31 male and female (not pregnant) subjects with healthy skin aged 18 years or older were enrolled in this single-center, randomized, vehicle-controlled, observer-blind study.

A gender-specific subdivision into groups was not necessary as the topical bioavailability is equally detectable in men and women. Only 'responders' to glucocorticosteroids, i.e. people who had shown adequate vasoconstriction to a topical glucocorticosteroid within the 2 weeks prior to the study, were eligible for this trial. The subjects were selected according to defined inclusion and exclusion criteria. One person dropped out of the study. Data from 30 subjects were valid for analysis.

The test product was a cream with $0.1 \%$ mometasone furoate, with a light texture and improved spreadability due to its water content of 33\% (Monovo ${ }^{\circledR}$ cream, Almirall Hermal GmbH, Reinbek, Germany; referred to as Mometasone cream). The reference products used were a class II glucocorticoid preparation with $0.1 \%$ triamcinolone acetonide (Triamgalen ${ }^{\circledR}$ Creme, Galen, Kiel, Germany; referred to as triamcinolone cream), a fatty cream with $0.1 \%$ mometasone furoate (class III) (Ecural ${ }^{\circledR}$ Fettcreme, Schering Plough (Merck Sharp \& Dohme Ltd), international trade name Elocon ${ }^{\circledR}$; referred to as mometasone comparator) and a cream with $0.05 \%$ of the class IV glucocorticoid clobetasol propionate (Dermoxin ${ }^{\circledR}$ Creme, GlaxoSmithKline plc., international trade name Dermovate ${ }^{\circledR}$; referred to as clobetasol cream). In addition, the active-ingredient-free vehicle to Mometasone cream was used as a negative control (for ingredients of the test product and reference products, see table 1).

An amount of approximately $50 \mu \mathrm{l}$ of each preparation was applied (as a single topical nonocclusive application) for $6 \mathrm{~h} \pm 10$ min to test fields $\left(2 \mathrm{~cm}^{2}\right)$ located on the volar surface of the forearms of the test subjects. One control field on each arm remained untreated. Skin color in the treated and untreated test fields was measured using chromametry, and the degree of vasoconstriction was clinically assessed and compared. Chromametric measurements and clinical assessments were performed at baseline and 1 , 2, 4, 6 and $18 \mathrm{~h}$ after the 6 -hour treatment.

Evaluation of Bioavailability and Safety

Blanching representing the vasoconstrictor properties of the respective test substance was evaluated as a primary variable by a chromametric measurement (redness value $\mathrm{a}^{*}$ ) of skin redness using a Chroma-Meter CR 300 (Minolta, Ahrensburg, Germany). Measurements were performed by softly placing the measuring head upon the test field and triggering. One measurement series consisted of three individual measurements taken in every field. The respective values were entered into the study database.

Clinical assessment as a secondary variable was determined by scoring. The degree of vasoconstriction in a treatment field compared to the untreated control field on the same forearm was clinically assessed by the investigator (independent observer) before the chromametry series, and scored as follows: $0=$ no vasoconstriction, $1=$ mild vasoconstriction, $2=$ moderate vasoconstric- 
tion, 3 = intense vasoconstriction. Safety was evaluated by medical history, screening, final clinical examination and the recording of adverse events (AEs). Laboratory parameters were not controlled during the course of the study.

\section{Statistics}

The primary efficacy variable consisted of the degree of redness of the skin, measured as the area under the time curve (AUC) of the baseline-corrected, untreated control-site-corrected chromaticity (a-values). Clinical assessment scores for the degree of vasoconstriction were recorded as a secondary variable. The chromametric a-value measurements were taken, and baseline adjustments were made for each test field and assessment point. These baseline-corrected chromametric values were referred to as $\mathrm{a}^{*}$ values. For each treatment group, the AUC was calculated for the respective a-values using the trapezoid rule. For the cardinally scaled a-values and the derived $\mathrm{a}^{*}$-values as well as for the AUC, descriptive statistics (valid number, mean, standard deviation, minimum and maximum) were carried out.

Clinical assessment scores were descriptively evaluated and the scores were presented in frequency tables. Score sums were also calculated.

The hierarchical approach was performed for the active study preparation and its corresponding vehicles. The overall significance level of $5 \%$ could be kept with this ordered test procedure.

\section{Psoriasis Plaque Test}

Test Subjects and Medication

The aim of the study was to determine the noninferiority of a topical mometasone formulation to a marketed comparator by evaluation of the antipsoriatic efficacy in a PPT. Between June and July 2008, 22 male and female (not pregnant) subjects with chronic plaque-type psoriasis, aged 18-75 years, were enrolled in this phase II, single-center, randomized, controlled, observer-blind study. A gender-specific subdivision into groups was not necessary as the antipsoriatic efficacy is equally detectable in men and in women. An up-to-date medical history was recorded and a physical examination performed during the 2 weeks before the study started. Patients with psoriasis guttata, psoriasis punctata, psoriasis erythrodermatica, psoriasis arthropathica and pustular psoriasis and those treated with antipsoriatics (except for salicylic acid in vaseline) in the 4 weeks preceding and/or during the study were excluded, as were those treated with any topical antipsoriatic (except for salicylic acid) in the 8 weeks preceding and/ or during the study. No patients dropped out. The data of all 22 subjects were valid for the intention-to-treat (ITT) and per-protocol analyses.

\section{Medication}

The test product used was Mometasone cream. The reference product was the mometasone comparator; the active-ingredientfree vehicle to Mometasone cream served as a negative control. Three test fields $\left(1.1 \mathrm{~cm}^{2}\right)$ in all were examined per subject, the treatments randomly assigned to the test fields in an observerblind manner, and the study preparations applied under Duhring chambers (diameter $12 \mathrm{~mm}$ inside and $14 \mathrm{~mm}$ outside) seated in holes punched in a hydrocolloid dressing (Varihesive ${ }^{\circledR}$, BristolMyers Squibb, Munich, Germany). The test fields were treated occlusively with either Mometasone cream (200- $\mu$ l formulation/ test field representing $0.2 \mathrm{mg}$ active ingredient/day), active-ingre- dient-free vehicle to Mometasone cream (200- $\mu$ l formulation/test field representing $0.0 \mathrm{mg}$ active ingredient/day), or the mometasone comparator $(200-\mu$ l formulation/test field representing 0.2 $\mathrm{mg}$ active ingredient/day) over a study period of 12 days (10 treatments). The total overall dosage of active ingredient was approximately $4.0 \mathrm{mg}$ mometasone furoate for every subject. On study days $2-6$ and $8-11$, the occluding chambers were removed and the treatments renewed once daily.

\section{Evaluation of Efficacy and Safety}

The hydrocolloid dressing was removed on study days 4, 8 and 12 , and sonography and clinical assessment were performed after removing preparation residues. Sonographic measurements were performed using a $20-\mathrm{MHz}$ high-frequency sonograph (DUBUSB, Taberna pro Medicum, Lueneburg, Germany). Depending on the echo patterns, components of the epidermis, dermis and subcutis were addressed to allow for exact measurement of the skin thickness. The inflammatory psoriatic infiltrate was seen as a clearly definable echo lucent band below the entrance echo. The thickness of the echo lucent psoriatic band was determined and documented. On study days 4,8 , and 12 , clinical assessment of the test fields was performed using a 5 -point score $(-1=$ worsened, 0 = unchanged (no effect), 1 = slight improvement, 2 = clear improvement but not completely healed, 3 = completely healed). A comparison was made with the untreated plaque beneath the hydrocolloid dressing. Clinically apparent differences in erythema and infiltration contributed to this global assessment. On study days 1 and 12, photo documentation and clinical examination were performed. Safety was evaluated by screening, final clinical examinations and the recording of AEs.

\section{Statistics}

The primary efficacy variable was the AUC calculated from the infiltrate thickness differences to baseline, established for the 3 measuring points following the baseline visit, separately. Secondary variables were the infiltrate thickness (sonography), and the clinical assessment (scores), assessed or measured at the various test points. The aim of this study was to prove the noninferiority of Mometasone cream to the mometasone comparator using a noninferiority margin $\Delta=250$ with respect to the AUC of change to baseline in infiltrate thickness, with a lower AUC being superior. The secondary endpoint of superiority of Mometasone cream to the active-ingredient-free vehicle, with respect to the AUC of change to baseline in infiltrate thickness, was also assessed by the confidence interval (CI) method. The additional secondary endpoints, i.e. changes to baseline in, and sonographic measurements of infiltrate thickness, clinical scores for the assessment of efficacy and adverse effects were evaluated by means of descriptive statistics.

\section{Dermal Tolerability Test}

Test Subjects and Medication

The study also aimed to determine the dermal tolerability of Mometasone cream on intact skin following repeated application over a 21-day treatment period. Between May and June 2008, 33 male and female (not pregnant) volunteers - aged 18 or older with healthy skin in the area of the test fields (on which reddening could easily be recognized) were enrolled in this single-center, randomized, controlled study which was double-blind for the study preparations. One subject dropped out. Data from all 33 
Fig. 1. Vasoconstriction assay: mean AUC baseline-corrected, untreated controlsite-corrected redness values $\left(\mathrm{a}^{*}\right)$ and $95 \%$ CI.

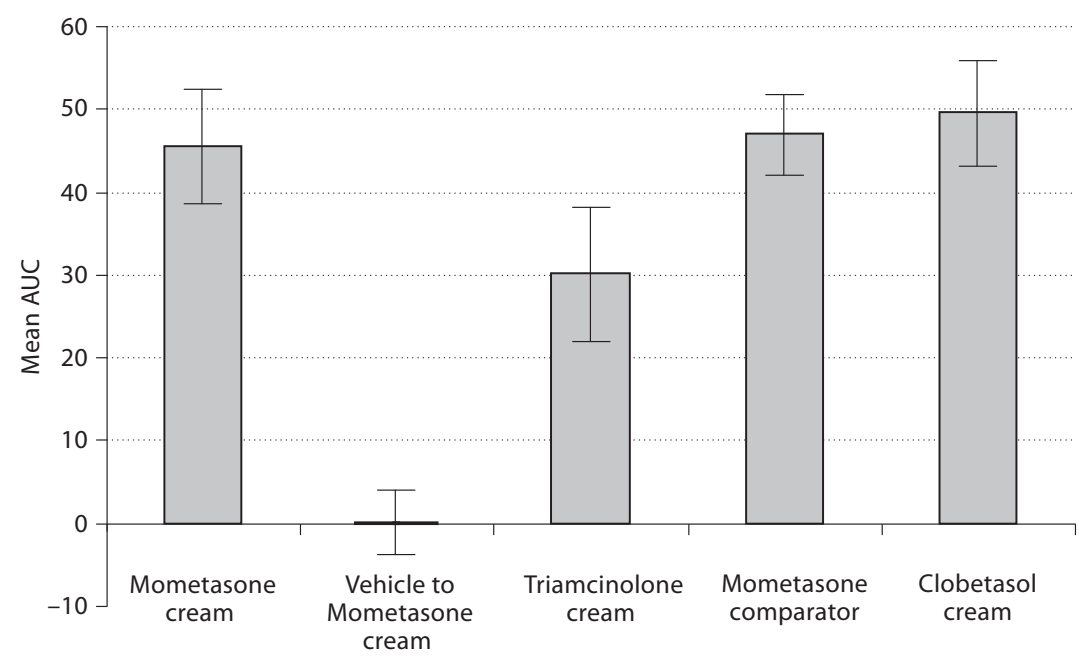

subjects were valid for safety and ITT analyses. Data from 31 subjects were valid for per-protocol analysis; these subjects received all treatments.

\section{Medication}

The test product used was Mometasone cream as described above. The reference products were the active-ingredient-free vehicle to Mometasone cream, purified water as a negative control and $0.3 \%$ sodium dodecyl sulfate in water (SDS) as a positive control. Altogether, 4 test fields on intact skin on the back were examined. The test fields were treated occlusively, using special test chambers once daily (approx. $100 \mu \mathrm{l} /$ test field of $2.5 \mathrm{~cm}^{2}$ ) with the study preparations and controls during a 21-day treatment period (18 treatments).

\section{Evaluation of Tolerability and Safety}

Clinical assessment of the test fields was performed on study days 2-6, 8-13, 15-20 and on day 22. Dermal reactions were clinically assessed using a score prior to renewed application on study days 2-21 and on day 22. Nonspecific local irritating reactions to the study preparations were evaluated. Safety was evaluated by screening, final clinical examinations and the recording of AEs.

\section{Statistics}

To summarize the tolerability, a cumulative irritation index was calculated based on the sum of the cumulative irritation scores for all subjects on day 22. Tolerability data were analyzed by treatment and day using descriptive statistical methods. Differences between the treatments were tested by the exact Wilcoxon signed-rank test at level $\alpha=0.05$. As this was an exploratory study, no adjustment for multiple testing was performed and the obtained $\mathrm{p}$ values were only interpreted descriptively.

\section{Results}

\section{Vasoconstriction Assay}

The blanching effect observed with Mometasone cream was comparably pronounced in comparison to that seen with the mometasone comparator and clobetasol cream, and superior to that of triamcinolone cream. The activeingredient-free vehicle to Mometasone cream had no relevant blanching effect. The chromametric measurements demonstrated a clear reduction in skin redness for Mometasone cream and the reference products mometasone comparator and clobetasol cream. Similar mean AUC values were noted for Mometasone cream, the mometasone comparator and clobetasol cream (45.57, 46.95 and 49.55, respectively). A lower mean AUC value was noted for triamcinolone cream (30.08). No-to-minimal blanching was noted in the fields treated with the vehicle cream (mean AUC $=0.11$ ) (fig. 1). The maximum mean baseline-corrected, untreated control-site-corrected a-value of Mometasone cream $18 \mathrm{~h}$ after the 6-hour treatment was 3.62. A similar reduction in skin redness was observed for the mometasone comparator and clobetasol cream (mean baseline-corrected, untreated control-site-corrected a-values $=\mathrm{a}^{*}$-values; 3.80 and 3.62 , respectively). A lower maximum mean a-value (baseline-corrected, untreated control-site-corrected) was noted for triamcinolone cream (2.35), and a value just above zero indicated that the vehicle to Mometasone cream had no blanching effect.

In the statistical analyses, the lower 95\% CI limits of the AUC of Mometasone cream, triamcinolone cream, 


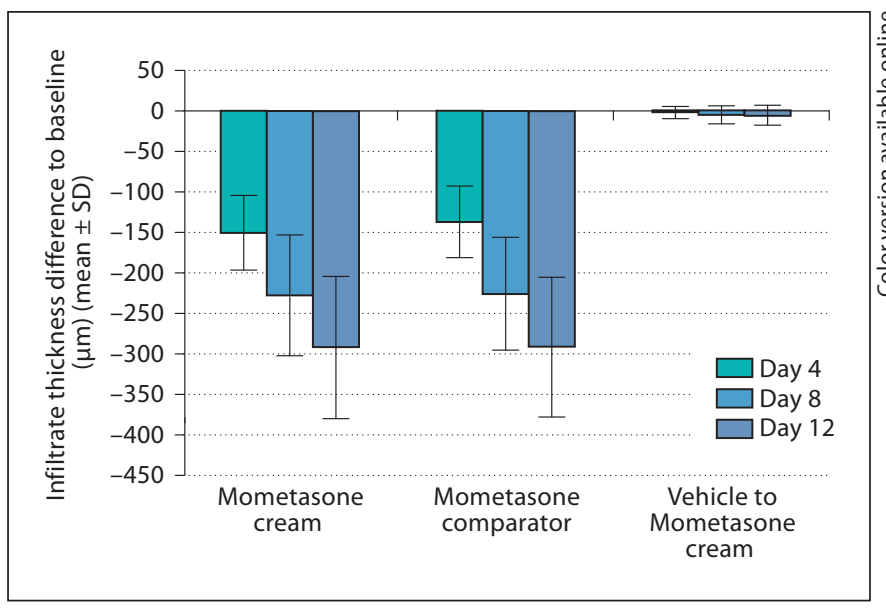

Fig. 2. Psoriasis plaque assay: mean infiltrate thickness difference to baseline $(\mu \mathrm{m})$.

Table 2. Vasoconstriction assay: clinical assessment $18 \mathrm{~h}$ after the 6-hour treatment $(\mathrm{n}=30)$

\begin{tabular}{|c|c|c|c|c|c|c|}
\hline & $1 \mathrm{~h}$ & $2 \mathrm{~h}$ & $4 \mathrm{~h}$ & $6 \mathrm{~h}$ & $18 \mathrm{~h}$ & Pooled \\
\hline \multicolumn{7}{|c|}{ Mometasone cream } \\
\hline Median score & 2 & 2 & 2 & 3 & 1 & \\
\hline Sum score & 63 & 65 & 72 & 76 & 25 & 301 \\
\hline \multicolumn{7}{|c|}{ Vehicle to Mometasone cream } \\
\hline Median score & 0 & 0 & 0 & 0 & 0 & \\
\hline Sum score & 3 & 2 & 1 & 1 & 0 & 7 \\
\hline \multicolumn{7}{|c|}{ Triamcinolone cream } \\
\hline Median score & 1 & 1 & 2 & 2 & 0.5 & \\
\hline Sum score & 30 & 35 & 44 & 51 & 17 & 177 \\
\hline \multicolumn{7}{|c|}{ Mometasone comparator } \\
\hline Median score & 2 & 2 & 3 & 3 & 1 & \\
\hline Sum score & 61 & 71 & 79 & 80 & 28 & 319 \\
\hline \multicolumn{7}{|l|}{ Clobetasol cream } \\
\hline Median score & 2 & 2 & 2.5 & 3 & 1 & \\
\hline Sum score & 50 & 62 & 69 & 75 & 34 & 290 \\
\hline
\end{tabular}

Median score and sum score: $0=$ no vasoconstriction, $1=$ mild vasoconstriction, 2 = moderate vasoconstriction, 3 = intense vasoconstriction.

the mometasone comparator and clobetasol cream were greater than zero. Therefore, it could be concluded that these 4 preparations were effective with respect to blanching. In the hierarchical testing, it was shown that Mometasone cream was more effective than the respective vehicle (not shown). The noninferiority of Mometasone cream to the comparators of lower strength (triamcinolone cream) and similar strength (mometasone compara- tor) could be demonstrated in all 3 cases considering a $20 \%$ margin. The noninferiority of Mometasone cream to the higher-strength comparator clobetasol cream could not be confirmed.

The clinical assessment reflected the results of the chromametric investigation (table 2). Moderate-to-intense vasoconstriction was noted in the test fields treated with Mometasone cream, mometasone comparator and clobetasol cream in nearly all subjects, and in the test fields treated with triamcinolone cream in more than half of the subjects. The vasoconstriction achieved with Mometasone cream was comparable to the effect seen for the mometasone comparator and clobetasol cream and superior to the effect seen for triamcinolone cream (table 2). In the test fields treated with the vehicle cream, the majority of the subjects showed no vasoconstriction. In this study, no AEs occurred and no observations related to safety were recorded. The final physical examination at the end of the study did not show abnormal findings in any of the subjects.

\section{Psoriasis Plaque Test}

Mometasone cream demonstrated a strong positive effect in the treatment of psoriasis in the PPT. The antipsoriatic effect of Mometasone cream was comparable to the effect seen for the mometasone comparator on the basis of the sonographic measurements (fig. 2). In the inferential analyses of the AUC of change to baseline in infiltrate thickness, the noninferiority of Mometasone cream to the mometasone comparator could be shown (table 3). The upper CI limit (68.8) was lower than the inferiority margin $\Delta=250$. The nearly identical mean percentaged reductions in infiltrate thickness after 12 days of treatment with Mometasone cream and the mometasone comparator (-70.16 and $-70.53 \%$, respectively) as well as the similar mean AUC values (-2,037.0 and $-1,981.3$, respectively) underlined the comparability of both formulations. As expected, no relevant antipsoriatic effect was noted for the active-ingredient-free vehicle. After 12 days of treatment with the vehicle, a percent reduction of $1.59 \%$ was noted and the AUC was clearly higher than for the 2 active formulations (-47.1). The superiority of Mometasone cream $(0.1 \%$ mometasone furoate) to the vehicle, with respect to the AUC of change to baseline in infiltrate thickness, was proven since the upper CI of the difference of these 2 formulations $(-1,719.8)$ was below 0 (table 3).

The global clinical assessment supported the results of the sonographic measurements. Comparable clinical improvement was seen for both Mometasone cream and the 
Table 3. PPT: inferential analyses of AUC of change to baseline in infiltrate thickness $(\mu \mathrm{m})$ for the ITT population

\begin{tabular}{|c|c|c|c|c|c|}
\hline Treatment $\mathrm{T}$ & Treatment R & $\begin{array}{l}\text { Mean AUC of change } \\
\text { to baseline in infiltrate } \\
\text { thickness }(\mathrm{T})\end{array}$ & $\begin{array}{l}\text { Mean AUC of change } \\
\text { to baseline in infiltrate } \\
\text { thickness (R) }\end{array}$ & $\begin{array}{l}\text { Mean AUC } \\
\text { differences } \\
(\mathrm{T}-\mathrm{R})\end{array}$ & $\begin{array}{l}95 \% \text { Two-sided }{ }^{3} \mathrm{CI} \\
\text { of } \mathrm{T}-\mathrm{R}\end{array}$ \\
\hline \multicolumn{6}{|l|}{ ITT population } \\
\hline Mometasone cream & Mometasone comparator & $-2,037.0$ & $-1,981.3$ & -55.7 & $-180.1 /-68.8^{1}$ \\
\hline Mometasone cream & vehicle to Mometasone cream & $-2,037.0$ & -47.1 & $-1,989.9$ & $-2,260.0 /-1,719.8^{2}$ \\
\hline
\end{tabular}

mometasone comparator, whereas no clinical improvement was seen with the active-ingredient-free vehicle. The course of the clinical assessment scores was nearly identical for Mometasone cream and the mometasone comparator (not shown). After 12 days of treatment with Mometasone cream and the mometasone comparator, a distinct improvement but not complete healing (score = 2) was noted in most of the subjects (16 of 22 , each). A slight improvement (score $=1$ ) was noted in 5 subjects and 'completely healed' (score $=3$ ) in 1 subject for both treatments, respectively. The median was 2 for both formulations on study day 12 . In nearly all subjects after 12 days of treatment with the active-ingredient-free vehicle, no effect (score $=0$ ) was seen. Worsening $($ score $=-1$ ) was not noted in any of the subjects.

Only 1, nonserious AE (diarrhea) was reported in this study. The final physical examination did not show abnormal findings in any of the subjects. The dermal tolerability was good and comparable for all study preparations - even under the occlusive conditions in this study.

\section{Dermal Tolerability Test}

Under the study conditions with occlusive topical application once daily for 21 days, Mometasone cream was moderately tolerated. Of the volunteers treated with Mometasone cream, 56.3\% showed erythematous score 1 reactions, compared to $37.5 \%$ of those treated with the vehicle (not shown). In both groups treated with Mometasone cream or with the vehicle, $21.9 \%$ of the subjects showed erythematous score 2 reactions. At the end of the study (day 22), $87.6 \%$ of the subjects treated with Mometasone cream and $96.9 \%$ of the subjects treated with the vehicle did not show signs of clinically relevant skin irritation (score 0 and 1 reactions). The total score sum for days 2-22 was 337 of a possible maximum of 2,316 expressed as the cumulative irritation index: $337 / 2,316$ (14.6\%) for Mometasone cream. The cumulative irritation index for the vehicle for days 2-22 was 228/2,316 (9.8\%), for the negative control (purified water) $4 / 2,316$ $(0.2 \%)$ and for the positive control ( $0.3 \%$ SDS) $1,284 / 2,316$ (55.4\%).

The cumulative irritation score of Mometasone cream for day 22 was clearly higher compared to the corresponding vehicle $(\mathrm{p}=0.0289)$ and the negative control $(\mathrm{p}<0.0001)$, but lower compared to the positive control $(\mathrm{p}<0.0001)$ (not shown). The vehicle cream had a cumulative irritation score lower than the positive control and higher than the negative control ( $\mathrm{p}<0.0001$ each). Altogether 5 nonserious AEs in 4 subjects were reported. One, gastroenteritis, was classified as moderate and the subject discontinued the study; all others, headache, acute hay fever, injury of upper lip and nausea, were classified as mild. In 4 AEs, the relationship to study medication was considered to be unlikely, and in 1 to not be related. There were no other relevant observations related to safety.

\section{Discussion}

For five decades, glucocorticoids have been used as suitable medications for the treatment of skin disorders associated with inflammatory processes [1-3]. As the long-term use of older glucocorticoids was often limited by side effects such as skin atrophy [4], new steroids were developed in the late 1980s with the object of increasing efficacy and reducing the incidence of adverse effects. Mometasone furoate is one of these new derivatives [25]. The agent offers a high local concentration at the site of 
application, the extended persistence of which is associated with a low absorption rate into the systemic circulation [8]. Due to its potency (class III steroid), its low percutaneous absorption, low systemic toxicity and low atrophogenic potential/risk of sensitization $[7,9,26,27]$ and thus a favorable benefit/risk ratio [7, 8], topically applied mometasone furoate has emerged as a standard medication for the treatment of inflammatory skin disorders [ 9 , $28,29]$.

However, not only the active pharmaceutical ingredient itself but various additional factors such as the base, penetration enhancers and other additives influence the activity of a topical formulation $[8,12-15,25,30]$, showing that the efficacy of a glucocorticoid formulation is dependent on the chosen vehicle. Kulhalli et al. [8] demonstrated this for mometasone furoate, whereas Korting et al. [17] found that a cream and an ointment which contain the same concentration of mometasone furoate do not differ in their activity.

Regardless of the role of the vehicle for the efficacy of a glucocorticoid formulation in general, and of mometasone furoate formulation in particular, patient compliance plays an additional and crucial role for glucocorticoid efficiency [18] - an aspect that should increasingly be taken into consideration in the treatment of skin diseases. As patients with inflammatory skin disease may prefer light creams to fatty creams with respect to convenient, daily application [publication in preparation], the introduction of a light cream should be a valuable addition to our therapeutic armamentarium.

In the studies presented here, we could demonstrate the topical bioavailability, antipsoriatic efficacy and tolerability of Mometasone cream, a new light cream $(\mathrm{O} / \mathrm{W}$ $60 / 40$ emulsion) with mometasone furoate $0.1 \%$ with a water content of $33 \%$. In the first study we could demonstrate a strong blanching effect of Mometasone cream using the vasoconstrictor assay (tables 2,3). The effect was comparable to that of the mometasone comparator, a fatty cream with mometasone furoate $0.1 \%$ with a water content $<5 \%$, and stronger than the effect seen for triamcinolone cream (fig. 1). The topical bioavailability of all active formulations was shown by chromametric measurement and clinical assessment. As expected, no relevant blanching effect was seen for the active-ingredientfree vehicle to Mometasone cream. As expected, the bioavailability of the active ingredient mometasone furoate $(0.1 \%)$ was similar for Mometasone cream and the mometasone comparator.

This result could also be supported by means of a PPT, a suitable method for the assessment of antipsoriatic ac- tion [23]. In this assay, a strong antipsoriatic effect comparable to that of the mometasone comparator was found for Mometasone cream. A relevant and nearly identical reduction in the mean infiltrate thickness and similar mean AUC values was noted with both $0.1 \%$ mometasone furoate-containing formulations (fig. 2) - a result confirmed by the clinical assessment data. A specific analysis of the data established the noninferiority of Mometasone cream to the mometasone comparator with respect to the AUC of change to baseline in infiltrate thickness. The fair tolerability of Mometasone cream, as observed in both tests, could also be confirmed in the dermal tolerability assay presented in this paper. Under the conditions of the dermal tolerability study, both Mometasone cream and its active-ingredient-free vehicle demonstrated a mild-tomoderate irritant potential.

In summary, both preparations - Mometasone cream and the mometasone comparator - showed a favorable benefit/risk ratio and both could, in particular, be considered for the treatment of acute und subacute dermatoses where creams are generally recommended [11]. However, in comparison to the mometasone comparator, Mometasone cream combines a high potency and good tolerability with the properties of a light cream, i.e. easy and convenient application, characteristics which are appreciated by patients with inflammatory skin diseases.

\section{Conclusion}

Mometasone cream, a new light cream (O/W 60/40 emulsion) with mometasone furoate $0.1 \%$, displays a similar efficacy and tolerability to the mometasone comparator, but also the properties of a light cream. This makes this topical medication a viable alternative when it comes to the treatment of acute inflammatory skin diseases.

\section{Acknowledgments}

The authors thank the colleagues of bioskin $\mathrm{GmbH}$ for performing the tests.

\section{Disclosure Statement}

The preparation of this manuscript was supported by an educational grant to C.S. from Almirall Hermal. H.C.K. collaborates with Almirall Hermal in the development of topical drugs for skin diseases. Data analysis and interpretation were not influenced by the company. 


\section{References}

1 Korting HC, Kerscher M, Schäfer-Korting M: Topical glucocorticoids with improved benefit/risk ratio: do they exist? J Am Acad Dermatol 1992;27:87-92.

2 Surber C, Itin PH, Bircher AJ, Maibach HI: Topical corticosteroids. J Am Acad Dermatol 1995;32:1025-1030.

3 Hughes J, Rustin M: Corticosteroids. Clin Dermatol 1997;15:715-721.

4 Korting HC, Hülsebus E, Kerscher M, Greber R, Schäfer-Korting M: Discrimination of the toxic potential of chemically differing topical glucocorticoids using a neutral red release assay with human keratinocytes and fibroblasts. Br J Dermatol 1995;133:54-59.

5 Proksch E: The role of emollients in the management of diseases with chronic dry skin. Skin Pharmacol Physiol. 2008;21:75-80.

6 Braun-Falco O, Plewig G, Wolff HH: Dermatologie und Venerologie, ed 4. Berlin, Springer, 2002.

7 Kerscher MJ, Hart H, Korting HC, Stalleicken D: In vivo assessment of the atrophogenic potency of mometasone furoate, a newly developed chlorinated potent topical glucocorticoid as compared to other topical glucocorticoids old and new. Int J Clin Pharmacol Ther 1995;33:187-189.

8 Kulhalli P, Chevli T, Karnik R, Sheth M, Mulgaonkar N: Comparative potency of formulations of mometasone furoate in terms of inhibition of 'PIRHR' in the forearm skin of normal human subjects measured with Laser Doppler Velocimetry. Indian J Dermatol Venereol Leprol 2005;71:170-174.

9 Prakash A, Benfield P: Topical mometasone. A review of its pharmacological properties and therapeutic use in the treatment of dermatological disorders. Drugs 1998;55:145163.

10 Luger TA: Topische Dermatotherapie mit Glukokortikoiden; in Korting HC, Callies R, Reusch M, Schlaeger M, Sterry W (eds): Dermatologische Qualitätssicherung, vol 6. Leitlinien und Empfehlungen. Berlin, ABW Wissenschaftsverlag, 2009, pp 943-951.

11 Wiedersberg S, Leopold CS, Guy RH: Bioavailability and bioequivalence of topical glucocorticoids. Eur J Pharm Biopharm 2008;68:453-466.
12 Olsen EA: A double-blind controlled comparison of generic and trade-name topical steroids using the vasoconstriction assay. Arch Dermatol 1991;127:197-201.

13 Ayres JW, Hooper G: Assessment of the skin penetration properties of different carrier vehicles for topically applied cortisol. Br J Dermatol 1978;99:307-317.

14 Poulsen J, Rorsman H: Ranking of glucocorticoid creams and ointments. Acta Derm Venereol 1980;60:57-62.

15 Korting HC: Influence of glucocorticoid substances and the vehicle on skin irritancy: determination by profilometry. Curr Probl Dermatol 1993;21:140-146.

16 Sequira J, Berardi M, Chan TM, Letarte J, Malchow R, Pramanick B, Wolkoff HN: Assessing equivalence of innovator and generic formulations of betamethasone dipropionate cream and ointment. Clin Ther 1991;13: 687-694.

17 Korting HC, Maslen K, Gross G, Willers C: Vergleich der Wirksamkeit verschiedener topischer Glukokortikoidcremes und -salben im Vasokonstriktionstest: Überlegenheit von Hydrocortisonbutyrat gegenüber Hydrocortison. J Dtsch Dermatol Ges 2005; 3:348-353.

18 Kirkland R, Pearce DJ, Balkrishnan R, Feldman SR: Critical factors determining the potency of topical corticosteroids. J Dermatol Treat 2006;17:133-135.

19 Haigh JM, Kanfer I: Assessment of topical corticosteroid preparations: the human skin blanching assay. Int J Pharm 1984;19:245262.

20 Brown PH, Teeluckisingh S, Matusiewicz SP, Greening AP, Crompton GK, Edwards CRW: Cutaneous vasoconstrictor response to glucocortisteroids in asthma. Lancet 1991; 337:576-580.

21 Borelli C, Gassmueller J, Fluhr JW, Nietsch $\mathrm{KH}$, Schinzel S, Korting HC: Activity of different desoximetasone preparations compared to other topical corticosteroids in the vasoconstriction assay. Skin Pharmacol Physiol 2008;21:181-187.
22 Cornell RC: Clinical trials of topical corticosteroids in psoriasis: correlations with the vasoconstrictor assay. Int J Dermatol 1992; 31(suppl 1):38-40.

23 Dumas KJ, Scholtz JR: The psoriasis bio-assay for topical corticosteroid activity. Acta Derm Venereol 1972;52:43-48.

24 Dumas KJ, Scholtz JR: Psoriasis-Plaque Test; in Wendt H, Frosch PJ (eds): Clinico-Pharmacological Models for the Assay of Topical Corticoids. Basel, Karger, 1982, pp 31-35.

25 Koivukangas V, Karvonen J, Risteli J, Oikarinen A: Topical mometasone furoate and betamethasone-17-valerate decrease collagen synthesis to a similar extent in human skin in vivo. Br J Dermatol 1995;132:66-68.

26 Wilkinson SM, Beck MH: Fluticasone propionate and mometasone furoate have a low risk of contact sensitization. Contact Dermatitis 1996:34:365-366.

27 Hoffmann K, Auer T, Stücker M, Hofmann A, Altmeyer P: Comparison of skin atrophy and vasoconstriction due to mometasone furoate, methylprednisolone and hydrocortisone. J Eur Acad Dermatol Venereol 1998; 10 : 137-142.

28 Medansky RS, Bressinck R, Cole GW, Deeken JH, Ellis CN, Guin JD, Herndon JH, Lasser AE, Leibsohn E, Menter MA, et al: Mometasone furoate ointment and cream 0.1 percent in treatment of psoriasis: comparison with ointment and cream formulations of fluocinolone actinide 0.025 percent and triamcinolone acetonide 0.1 percent. Cutis 1988;42:480-485.

29 Katz HI, Prawer SE, Watson MJ, Scull TA, Peets EA: Mometasone furoate ointment $0.1 \%$ vs. hydrocortisone ointment $1.0 \%$ in psoriasis. Atrophogenic potential. Int J Dermatol 1989;28:342-344.

30 Faergemann J, Christensen O, Sjövall P, Johnssson A, Hersle K, Nordin P, Edmar B, Svensson A: An open study of efficacy and safety of long-term treatment with mometasone furoate fatty cream in the treatment of adult patients with atopic dermatitis. J Eur Acad Dermatol Venereol 2000;14:393-396. 